\title{
Identifying the Intellectual Structure of Patient Safety Studies
}

\author{
Cheng Hua Wang, Yuan Duen Lee, Hui Lin Chou, Jen Hwa Kuo, and Ching-Hsiang Hsieh
}

\begin{abstract}
To explore the intellectual structure of patient safety research in the last decade, the most crucial publications, most influential scholars, as well as the correlations among the publications of these scholars were identified. In this study, bibliometric techniques (citation analysis and cocitation analysis) were used to investigate the intellectual pillars of the patient safety literature. By analyzing 123080 citations of 2425 articles regarding patient safety, published from 2003 to 2012 and obtained from the Science Citation Index and Social Sciences Citation Index databases, a knowledge network of patient safety studies was mapped. The mapping results can be used to help identify the direction of patient safety research and provide a valuable tool for researchers to access the literature in this field.
\end{abstract}

Index Terms-Bibliometric technique, human factors, intellectual structure, patient safety.

\section{INTRODUCTION}

Patient safety is often viewed as the freedom from medical error and accidental harm [1], and it is a topic with extensive economic and human implications [2]. From a systemic perspective, the evaluation of the overall safety within an organization involves the assessment of integrated human and mechanical (technical) systems. Therefore, it is appropriate to speak regarding the entire set of situations and interactions that might involve humans and machines when examining safety in this context [3]. The use of human factors and ergonomics (HFE) tools, methods, concepts, and theories has been advocated by various experts and organizations to improve patient safety, and several papers that specifically address HFE issues related to patient safety have been published [4]. In this study, the intellectual structure of patient safety was discussed from a human factors perspective.

In this paper, the problems arising from the struggle to establish patient safety was empirically investigated by examining the literature by using citation and cocitation data obtained from Technovation. A brief review of similar bibliometric studies is presented to introduce the approach, accompanied by a description of the data. The principal investigation was a factor analysis, which was performed to determine the latent structure underlying the patient safety literature.

Citation and cocitation are essential research tools for evaluating the core knowledge of an academic field [5], [6]. A

Manuscript received November 10, 2013; January 17, 2014

Cheng Hua Wang, Yuan Duen Lee, Hui Lin Chou, and Jen Hwa Kuo are with the Graduate School of Business and Operations Management of the Chang Jung Christian University, Taiwan (e-mail: \{huager, ydlee\}@mail.cjcu.edu.tw, \{hhuillin, dynaopto\}@gmail.com ).

Ching-Hsiang Hsieh is with the Chiayi Yang Ming Hospital (e-mail: cyymhd001@yahoo.com.tw). few studies using bibliometrics to examine leadership research exist [7], [8], but almost none has conducted cocitation analysis in the patient safety field. Therefore, conducting this study fills the gap in patient safety research by providing a detailed evaluation of applying citation and cocitation to patient safety research.

The aim of this study was to provide medical quality researchers with a unique map to improve their understanding of patient-safety-related publications and to provide a systematic and objective map of various themes and concepts in the development of the medical quality field. The linkages among publications were also identified and their statuses, positions, and contributions to the development of the patient safety field were verified. Citation and cocitation were the principal methods used. To explore the changes of main patient safety research in the last decade, the data was divided into two stages: the first 5 years and the second 5 years. A factor analysis was then conducted to map the intellectual structure of patient safety studies in these two periods. The changes in the key research topics and their implications in the evolution of patient safety research during the past decade are also discussed.

\section{STUDIES OF ACADEMIC LITERATURE: CITATION AND COCITATION ANALYSIS}

Various techniques can be used to examine a body of literature. The most frequently used method is the simple literature review whereby a highly subjective approach is used to structure earlier studies [9]. Objective and quantitative techniques have recently become popular because available online databases are increasing. Bibliometrics, the application of mathematical and statistical techniques to the study of publications and professional communications, is an essential approach in multiple fields [10]. Two of the most indispensable and widely used tools are citation and cocitation analysis. Citation analysis is based on the assumption that authors cite papers they consider crucial for the development of their research, and that heavily cited articles are more likely to have exerted a substantial influence on the subject than those that are less frequently cited [11]. This tool was popularized by the work of Garfield [12], who applied citation analysis to preexisting indexes, the Science Citation Index (SCI) and Social Sciences Citation Index (SSCI).

\section{A. Citation Analysis}

The citation analysis method is mainly used to analyze the reference phenomenon or objects of journals, papers, and authors, and to explore the relationship between the sources 
of literature and citations. Implementing this method can help researchers understand the current state of development of certain disciplines, the literature usage characteristics in these disciplines, the correlations among the disciplines in the literature, and future trends of research.

\section{B. Cocitation}

Cocitation is the frequency at which two documents or authors are cited together by recent papers [13], [14]. A cocitation analysis of documents is conducted by recording the number of papers that have cited any particular pair of documents and it is interpreted as a measure of the similarity of the content of the two documents. The approach is instrumental in identifying groupings of authors, topics, or methods, and can help people understand how these clusters interrelate [15]. Specifically, in cocitation studies, cocitation counts are compiled in matrix form and statistically scaled to record, at a distinct point in time, what is actually a changing and evolving structure of knowledge [16]. Therefore, cocitation analysis was considered an efficient method for measuring relationships and linkages between authors, papers, and journals to describe the mainstream or cutting-edge research in science [17].

\section{MethodOLOGY}

In this study, the SCI and SSCI were used for analysis. SCI and SSCI are widely used databases that include articles published in more than 8000 of the leading scholarly journals worldwide. Arguments that other online databases might also be used for such analysis exist; however, using SCI and SSCI provided the most comprehensive and most acceptable databases of patient safety publications. To collect the data, a key word was used to identify the relevant article titles and abstracts in the SCI and SSCI. Using "patient safety" and "human factor" as the keywords, 1317 journal articles were collected, and those articles cited 92394 publications as references.

The citation data used in this study included journal articles, authors, publication journals, publication dates, and cited references. Based on the objective of this study, the intellectual structure of the patient safety field between 2003 and 2012 was explored. This period was chosen because contemporary patient safety studies conducted during the last decade represent the most up-to-date and likely the most crucial research. Citation and cocitation analysis were the main methods used in this study. By using citation and cocitation analysis, three stages were assumed in this research, each of which required different approaches for examining the development of patient safety studies. First, the databases were identified as the sources of patient safety publications. Data collection and analysis techniques were then designed to collect information regarding research topics, authors, and journals on patient safety research.

Bibliometrics were employed to accomplish the following goals: 1) map the cocitation networks of the patient safety studies from the past 10 years; 2) examine the links between the primary scholars who authored key articles on patient safety research; and 3) provide a historical timeline perspective on the evolution of patient safety as a discipline.
The sampling period of a decade was divided into two half decades. The 123080 citation data items were manually collected, checked, subtotaled, and classified according to authors and the year of completion and were compared. The results were then interpreted and validated [18]. The analyses were conducted using Ucinet 6.0 for Windows [19].

\section{RESULTS}

\section{A. Citation Analysis}

To identify the key publications and scholars that have established the foundation of patient safety research, citation data were tabulated for each of the 2425 source documents and 123080 references by using Microsoft Excel. The citation analysis produced background statistics, as shown in the following tables. Table I lists the most cited journals related to patient safety during the previous decade, among which the New England Journal of Medicine, Journal of Clinical Oncology, and Blood were the top three most cited journals. The general pattern of the most cited journals showed that patient safety research features clinically, scientifically, and medically focused journals.

\begin{tabular}{lc}
\multicolumn{1}{c}{ TABLE I: THE MOST FREQUENTLY CITED JOURNALS: } & 2003-2012 \\
\hline \multicolumn{1}{c}{ Journal } & Total \\
& Citations \\
\hline New England Journal of Medicine & 3572 \\
Journal of Clinical Oncology & 3377 \\
Blood & 2330 \\
Lancet & 1913 \\
Cancer Research & 1528 \\
Proceedings of the National Academy of Sciences of & 1512 \\
the United States of America & \\
Arthritis and Rheumatism & 1318 \\
Nature & 1216 \\
Jama-Journal of the American Medical Association & 1162 \\
Clinical Cancer Research & 1091 \\
Science & 1069 \\
Circulation & 1063 \\
Journal of Immunology & 878 \\
Journal of Biological Chemistry & 872 \\
Gastroenterology & 810 \\
British Medical Journal & 792 \\
Journal of Clinical Investigation & 788 \\
\hline
\end{tabular}

The most cited and most influential documents by the most influential scholars were then identified using their total counts of citations within the selected journal articles. Tables II and III list the relevant publications, including books and journal articles. As shown in Table II, the most cited patient safety publications between 2003 and 2007 (the first 5 years) were "Use of Chemotherapy Plus a Monoclonal Antibody Against HER2 for Metastatic Breast Cancer That Overexpresses HER2" by Slamon, followed by the book Human Error by Reason, and "New Guidelines to Evaluate the Response to Treatment in Solid Tumors" by Therasse.

For the second five years (2008-2012), the most cited patient safety publication was "Use of Chemotherapy Plus a Monoclonal Antibody Against HER2 for Metastatic Breast Cancer That Overexpresses HER2" by Slamon. The other two most cited publications were "New Guidelines to Evaluate the Response to Treatment in Solid Tumors" by Therasse and "Human Breast Cancer: Correlation of Relapse and Survival 
with Amplification of the HER-2/Neu Oncogene" by Slamon (Table III).

\begin{tabular}{lc}
\multicolumn{2}{c}{ TABLE II: HIGHLY CITED ARTICLES: 2003-2007 } \\
\hline \multicolumn{1}{c}{ Full Citation Index For Document } & $\begin{array}{c}\text { Total } \\
\text { Citations }\end{array}$ \\
\hline Slamon DJ, 2001, NEW ENGL J MED, V344, P783 & 32 \\
Reason J., 1990, HUMAN ERROR & 24 \\
Therasse P, 2000, J NATL CANCER I, V92, P205 & 23 \\
Baert F, 2003, NEW ENGL J MED, V348, P601 & 22 \\
Cobleigh MA, 1999, J CLIN ONCOL, V17, P2639 & 22 \\
Hanauer SB, 2002, LANCET, V359, P1541 & 22 \\
Targan SR, 1997, NEW ENGL J MED, V337, P1029 & 22 \\
Leape LL, 1994, JAMA-J AM MED ASSOC, V272, P1851 & 21 \\
Lipsky PE, 2000, NEW ENGL J MED, V343, P1594 & 20 \\
Reason J, 2000, BRIT MED J, V320, P768 & 20 \\
Slamon DJ, 1987, SCIENCE, V235, P177 & 20 \\
Vogel CL, 2002, J CLIN ONCOL, V20, P719 & 20 \\
Brennanta, 1991, NEW ENGL J MED, V324, P370 & 18 \\
Keane J, 2001, NEW ENGL J MED, V345, P1098 & 18 \\
Present DH, 1999, NEW ENGL J MED, V340, P1398 & 17 \\
\hline
\end{tabular}

\begin{tabular}{lr}
\multicolumn{2}{c}{ TABLE III: HIGHLY CITED ARTICLES: 2008-2012 } \\
\hline \multicolumn{1}{c}{ Full Citation Index For Document } & Total \\
& Citations \\
\hline Slamon DJ, 2001, NEW ENGL J MED, V344, P783 & 79 \\
Therasse P, 2000, J NATL CANCER I, V92, P205 & 79 \\
Slamon DJ, 1987, SCIENCE, V235, P177 & 57 \\
Romond EH, 2005, NEW ENGL J MED, V353, P1673 & 52 \\
Reason J., 1990, HUMAN ERROR & 49 \\
Marty M, 2005, J CLIN ONCOL, V23, P4265 & 45 \\
Vogel CL, 2002, J CLIN ONCOL, V20, P719 & 42 \\
Geyer CE, 2006, NEW ENGL J MED, V355, P2733 & 39 \\
Piccart-Gebhart MJ, 2005, NEW ENGL J MED, V353, & 38 \\
P1659 & 37 \\
Takahashi K, 2006, CELL, V126, P663 & 36 \\
Takahashi K, 2007, CELL, V131, P861 & 35 \\
Reason J, 2000, BRIT MED J, V320, P768 & 35 \\
Yu JY, 2007, SCIENCE, V318, P1917 & 32 \\
Kohn LT, 2000, ERR IS HUMAN BUILDIN & 31 \\
Slamon DJ, 1989, SCIENCE, V244, P707 & \\
\hline
\end{tabular}

TABLE IV: HIGHLY CITED AUTHORS: 2003-2007

\begin{tabular}{lclc}
\hline Author & Frequency & Author & Frequency \\
\hline Sandborn WJ & 69 & Baselga J & 40 \\
Leape LL & 66 & Moreland LW & 40 \\
Slamon DJ & 64 & Kohn LT & 36 \\
Hanauer SB & 49 & Mease PJ & 32 \\
Weinblatt ME & 47 & Schreiber S & 32 \\
Rutgeerts P & 46 & Bernard GR & 31 \\
Vincent C & 46 & Lusher JM & 31 \\
Helmreich RL & 42 & Thomas EJ & 29 \\
Bates DW & 41 & Goodnough LT & 27 \\
Reason J & 41 & Sands BE & 27 \\
\hline
\end{tabular}

TABLE V: HiGHLY CITED AUTHORS: 2008-2012

\begin{tabular}{lclc}
\hline Author & Frequency & Author & Frequency \\
\hline Slamon DJ & 171 & Rall M & 58 \\
Baselga J & 105 & Reason J. & 57 \\
Reason J & 98 & Yu JY & 57 \\
Takahashi K & 80 & Bates DW & 55 \\
Therasse P & 79 & Helmreich RL & 55 \\
Perez EA & 76 & Marty M & 54 \\
Leape LL & 71 & Geyer CE & 53 \\
Carayon P & 70 & Romond EH & 53 \\
Sandborn WJ & 66 & Lingard L & 52 \\
Vincent C & 62 & Thomas EJ & 50 \\
\hline
\end{tabular}

When the journal articles and books were combined, the top six most cited scholars between 2003 and 2007 (the first 5 years) were Sandborn, Leape, Slamon, Hanauer, Weinblatt, and Rutgeerts (Table IV). For the second 5 years, the top six most cited scholars were Slamon, Baselga, Reason, Takahashi,
Therasse, and Perez (Table V). These scholars exerted the most influence on the development of the digital divide area and thus collectively define this field. Their contributions represent the focus of the main research in the field and thus provide us with an indication of the popularity of certain patient safety topics as well as their historical value.

\begin{tabular}{|c|c|c|c|}
\hline Timeline & Citations & Type & Title \\
\hline 1987 & 20 & $\mathbf{J}$ & $\begin{array}{l}\text { Human breast cancer- correlation of } \\
\text { relapse and survival with } \\
\text { amplification }\end{array}$ \\
\hline 1990 & 24 & B & Human Error \\
\hline 1991 & 18 & $\mathrm{~J}$ & $\begin{array}{l}\text { Incidence of Adverse Events } \\
\text { Negligence in Hospitalized-Patients }\end{array}$ \\
\hline 1994 & 21 & $\mathrm{~J}$ & Error in Medicine \\
\hline 1997 & 22 & $\mathrm{~J}$ & $\begin{array}{l}\text { Chimeric monoclonal antibody cA2 } \\
\text { to tumor necrosis factor alpha for } \\
\text { Crohn's disease }\end{array}$ \\
\hline 1999 & 22 & $\mathrm{~J}$ & $\begin{array}{l}\text { Efficacy and safety of humanized } \\
\text { anti-HER } 2 \text { monoclonal antibody in } \\
\text { women with HER2-overexpressing } \\
\text { metastatic breast cancer }\end{array}$ \\
\hline 1999 & 17 & $\mathrm{~J}$ & $\begin{array}{l}\text { Infliximab for the treatment of fistulas } \\
\text { in patients with Crohn's disease }\end{array}$ \\
\hline 2000 & 23 & $\mathrm{~J}$ & $\begin{array}{l}\text { New guidelines to evaluate the } \\
\text { response to treatment in solid Tumors }\end{array}$ \\
\hline 2000 & 20 & $\mathbf{J}$ & $\begin{array}{l}\text { Human error-models and } \\
\text { management }\end{array}$ \\
\hline 2001 & 32 & $\mathrm{~J}$ & $\begin{array}{l}\text { Chemotherapy plus a monoclonal } \\
\text { antibody against HER } 2 \text { for metastatic } \\
\text { breast cancer that overexpresses } \\
\text { HER2. }\end{array}$ \\
\hline 2001 & 18 & $\mathbf{J}$ & $\begin{array}{l}\text { Tuberculosis associated with } \\
\text { infliximab, a tumor necrosis factor } \\
\text { (alpha)-neutralizing agent }\end{array}$ \\
\hline 2002 & 22 & $\mathrm{~J}$ & $\begin{array}{l}\text { Maintenance infliximab for Crohn's } \\
\text { disease- the Accent I randomised trial }\end{array}$ \\
\hline 2002 & 20 & $\mathrm{~J}$ & $\begin{array}{l}\text { Efficacy and safety of trastuzumab as } \\
\text { a single agent in first-line treatment of } \\
\text { HER2-overexpressing metastatic } \\
\text { breast cancer }\end{array}$ \\
\hline 2003 & 22 & $\mathrm{~J}$ & $\begin{array}{l}\text { Influence of immunogenicity on the } \\
\text { long-term efficacy of infliximab in } \\
\text { Crohn's disease }\end{array}$ \\
\hline
\end{tabular}

TABLE VII: HISTORICAL TIMELINE OF PATIENT SAFETY:2008-2012

\begin{tabular}{|c|c|c|c|}
\hline Timeline & Citations & Type & Title \\
\hline 1987 & 57 & $\mathrm{~J}$ & $\begin{array}{l}\text { Human breast cancer- correlation of } \\
\text { relapse and survival with amplification }\end{array}$ \\
\hline 1989 & 31 & $\mathrm{~J}$ & $\begin{array}{l}\text { Studies of the HER- } 2 \text { Neu } \\
\text { Proto-Oncogene in Human-Breast and } \\
\text { Ovarian-Cancer }\end{array}$ \\
\hline 1990 & 49 & B & Hman Error \\
\hline 2000 & 79 & $\mathbf{J}$ & $\begin{array}{l}\text { New guidelines to evaluate the response } \\
\text { to treatment in solid Tumors }\end{array}$ \\
\hline 2000 & 35 & $\mathrm{~J}$ & Human error-models and management \\
\hline 2000 & 35 & $\mathrm{~J}$ & $\begin{array}{l}\text { To Err Is Human Building a Safer Health } \\
\text { System }\end{array}$ \\
\hline 2001 & 79 & $\mathrm{~J}$ & $\begin{array}{l}\text { Use of chemotherapy plus a monoclonal } \\
\text { antibody against HER } 2 \text { for metastatic } \\
\text { breast cancer that overexpresses HER } 2 \text {. }\end{array}$ \\
\hline 2002 & 42 & $\mathrm{~J}$ & $\begin{array}{l}\text { Efficacy and safety of trastuzumab as a } \\
\text { single agent in first-line treatment of } \\
\text { HER2-overexpressing metastatic breast } \\
\text { cancer }\end{array}$ \\
\hline 2004 & 27 & $\mathrm{~J}$ & 18 \\
\hline 2005 & 52 & $\mathrm{~J}$ & $\begin{array}{l}\text { Trastuzumab plus adjuvant } \\
\text { chemotherapy for operable } \\
\text { HER2-positive breast cancer }\end{array}$ \\
\hline 2006 & 39 & $\mathrm{~J}$ & $\begin{array}{l}\text { Lapatinib plus capecitabine for } \\
\text { HER2-positive advanced breast cancer }\end{array}$ \\
\hline 2006 & 37 & $\mathrm{~J}$ & $\begin{array}{l}\text { Induction of pluripotent stem cells from } \\
\text { mouse embryonic and adult fibroblast } \\
\text { cultures by defined factors }\end{array}$ \\
\hline
\end{tabular}




\section{B. Research Timeline}

The objective of this paper was to trace the evolution of the intellectual structure of the patient safety field. The historical timeline of research concepts, and the themes and methods in 2D scale will provide a clear overview of the patient safety research path in the period from 2003 to 2012 (Fig. 1 and Fig. 2). Dramatic changes are affecting the world of work; therefore, the main topics in patient safety studies are also changing. Common topics included increased human factor, the impact of patient safety, the shift from vertically integrated hierarchies to networks of specialists, hospital managers, and the change in the paradigm of performing safe operations from performing surgery to providing a service. In addition, the definition of work itself is evolving; the idea of a job as a fixed collection of tasks is disappearing, and there is a new emphasis on constantly evolving practices to fulfill the ever-increasing demands of patients. Hospital managers have a great opportunity to contribute to the betterment of human welfare in the context of these changes. However, leading this change rather than simply following it will require a break from traditional practices and a focus on rigorous research that addresses emerging trends. Several new and old topics and keywords demonstrate the view of patient safety as a dynamic entity in constant interaction with its environment, as shown in Table VI and Table VII, and Fig. 1 and Fig. 2. In other words, hospitals must adapt to the substantial changes that are occurring regarding precludes, management, and service values.

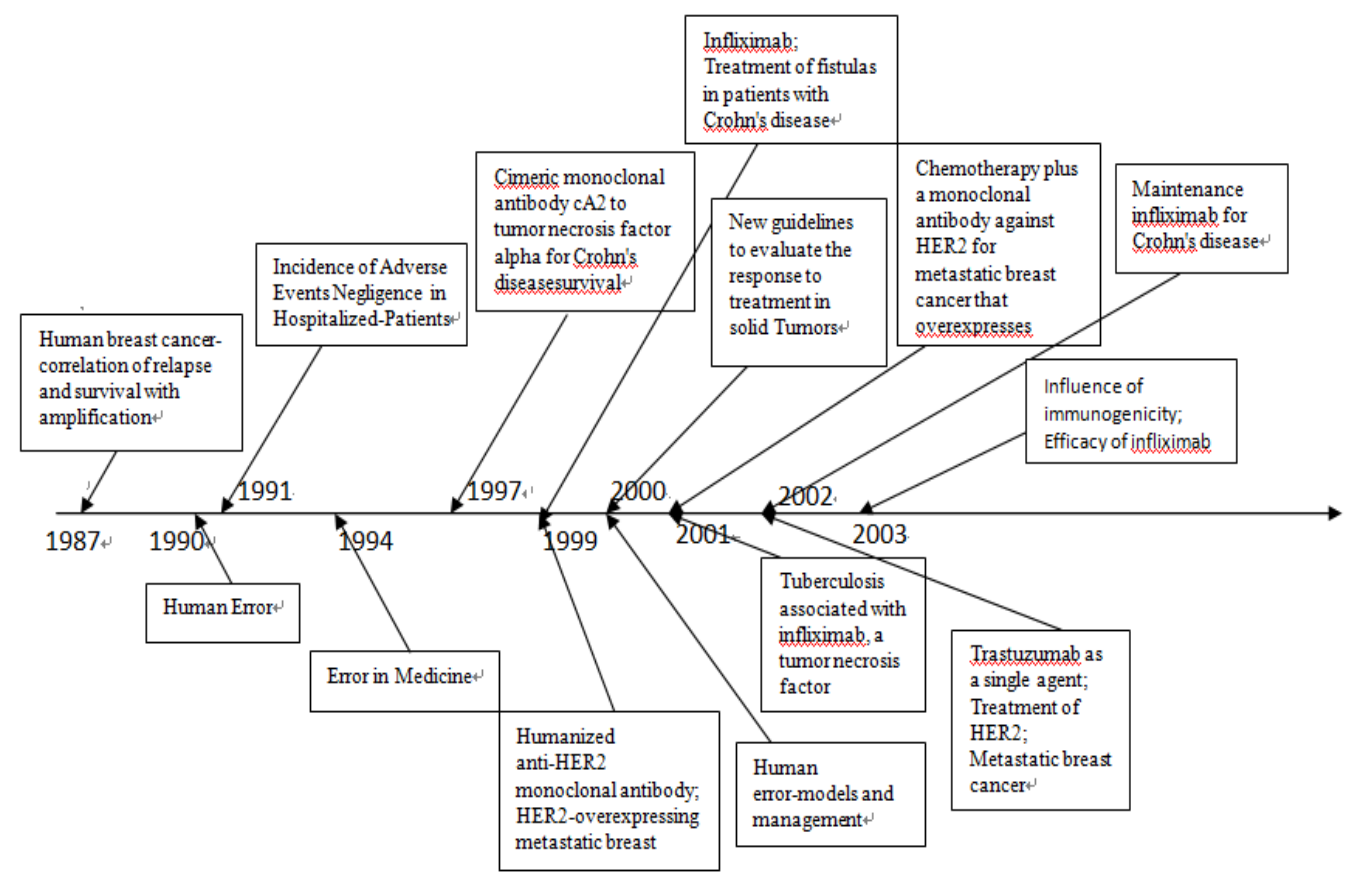

Fig. 1. Research topics and keywords historical timeline of patient safety: 2003-2007.

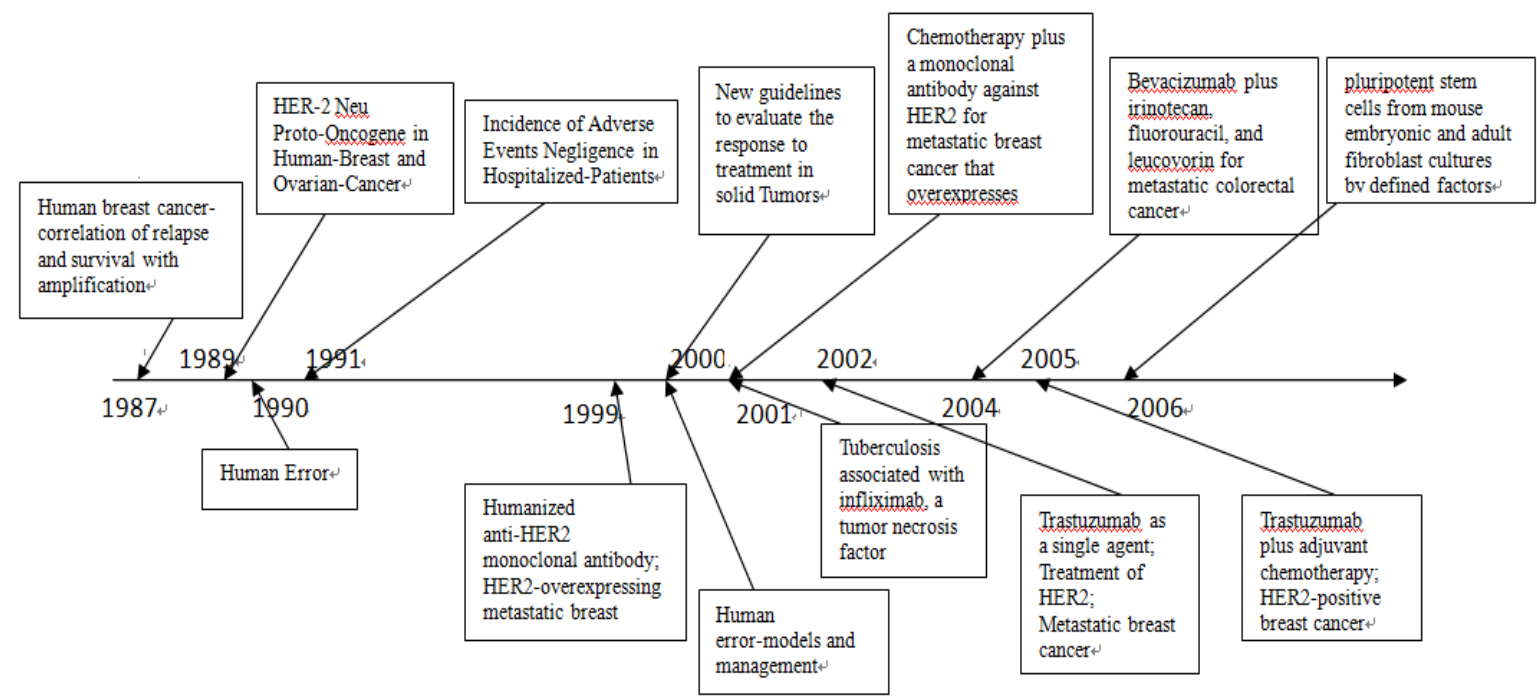

Fig. 2. Research topics and keywords historical timeline of patient safety: 2008-3012.

\section{CONCLUSION}

Extensive research on patient safety has been conducted during the past decade. In this study, patient safety research was investigated using citation and cocitation data published in the SCI and SSCI between 2003 and 2012. Through a 
factor analysis of the cocitation data, the intellectual structure of patient safety research was mapped.

The mapping of the intellectual structure of patient safety studies indicated that the field now has its own literature and that it has developed into a legitimate academic field. The publication of patient-safety-specific journals, such as the Journal of Nursing Administration, Journal of Advanced Nursing, and Journal of Nursing Management, indicates that patient safety has gained the status required for an independent research field. Because the patient safety field is still new and the analysis has shown that it has an evolving structure, it is believed that patient safety publication outlets will gain the popularity and prestige that is required to become a more prominent academic field when the current paradigms and key research themes in patient safety studies, how they interrelate, and what they represent have been identified. As the number of scholars and resources contributing to patient safety increases, an academic environment conducive to the cross-fertilization of research ideas will be formed and patient safety as a research field will gain more momentum for further development.

The contributions of this study are the following: 1) the research direction and the most influential studies in the patient safety field were identified; 2) the intellectual evolution of the field was traced by tracking the changes in the citation patterns over time; 3) the intellectual structure was empirically mapped; 4) theories in patient safety studies were identified; and 5) a valuable tool was provided for researchers to assess the literature in this field. Thus, the findings of this paper can help improve how academics and practitioners understand modern patient safety studies. The present study is distinct from previous reviews because this study focused on citation and cocitation analysis to identify key themes, concepts, and their relationships rather than on methodology (e.g., content analysis) or other narrower aspects of the patient safety field from the past decade.

\section{REFERENCES}

[1] L. L. Leape, "New world of patient safety 23rd annual samuel jason mixter lecture," Archives of Surgery, vol. 144, no. 5, pp. 394-398, 2009.

[2] K, Henriksen, J. B. Battles, M. A. Keyes, and M. L. Grady, "Agency for healthcare research and quality," Advances in Patient Safety: New Directions and Alternative Approaches, Rockville, MD: 2008, AHRQ Publication No 08-0034.

[3] P. C. Cacciabuea, and G. Vella, "Human factors engineering in healthcare systems: The problem of human error and accident management," International Journal of Medical Informatics, vol. 7, no. 9, pp. e1-e17, 2010.

[4] P. Carayon, "Human factors in patient safety as an innovation," Applied Ergonomics, vol. 41, no. 5, pp. 657-665, 2010.

[5] H. Small, "Co-Citation in the scientific literature: A new measure of the relationship between two documents," Journal of the American Society for Information Science, vol. 24, no. 4, pp. 265-269, 1973.

[6] I. V. Marshakova, "A system of document connections based on references," Scientific and Technical Information Serial of VINITI, vol. 6, no. 2, pp. 3-8, 1973.

[7] Y. D. Lee, Y. McLee, and C. F. Huang, "The status of leadership studies: Its invisible network of knowledge," International Journal of Management and Technology, vol. 1, no. 1, pp. 167-182, 2011.

[8] C. T. Kuo and Y. McLee, "Evolution of the intellectual structure of leadership studies in the last decade: Perspective on the invisible network of knowledge," The Journal of Human Resource and Adult Learning, vol. 8, no. 2, pp. 182-192, 2012.
[9] A. Drejer, "The discipline of management of technology, based on considerations related to technology," Technovation, vol. 17, no. 5, pp. 253-265, 1997.

[10] V. Diodato, Dictionary of Bibliometrics, Haworth Press, Binghamton, New York, 1994.

[11] Z. Ma, Y. Lee, and K. Yu, "Ten years of conflict management studies: Themes, concepts, and relationships," International Journal of Conflict Management, vol. 19, no. 3, pp. 234-248, 2008.

[12] E. Garfield, "Citation analysis as a tool in journal evaluation," Science, vol. 178, no. 4060, pp. 471-479, 1972.

[13] J. Alger, "Can RANK be used to generate a reliable author list for co-citation studies?" College and Research Libraries, vol. 57, no. 6, pp. 567-574, 1996.

[14] A. Pilkington and C. Liston-Heyes, "Is production and operations management a discipline? Acitation/co-citation study," International Journal of Operations and Production Management, vol. 19, pp. 7-20, 1999.

[15] H. G. Small, "Macro-Level changes in the structure of co-citation clusters: 1983-1989," Scientometrics, vol. 26, pp. 5-20, 1993.

[16] M. Y. Tsay, H. Xu, and C. W. Wu, "Author co-citation analysis of semiconductor literature," Scientometrics, vol. 58, no. 3, pp. 529-545, 2003.

[17] J. Alger, "Can RANK be used to generate a reliable author list for co-citation studies?" College Research Libraries, vol. 57, no. 6, pp. 567-574, 1996.

[18] S. P. Borgatti, M. G. Everett, and L. C. Freeman, "Ucinet 6 for Windows," Harvard: Analytic Technologies, 2002.

[19] H. G. Small, "Macro-Level changes in the structure of co-citation clusters: 1983-1989," Scientometrics, vol. 26, pp. 5-20, 1993.

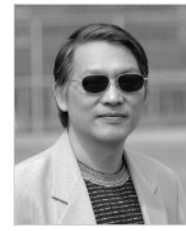

Cheng Hua Wang is an associate professor at the doctoral program at Chang Jung Christian University, Taiwan. He received his Ph.D. degree from the Department of Industrial Engineering and Engineering Management at National Tsing Hua University, Taiwan. His research interests include operations research, enterprise resource planning, and tourism management.

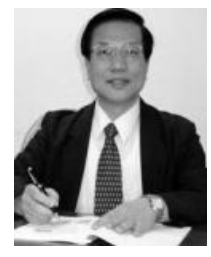

Yuen Duan Lee is a professor at the Graduate School of Business and Operations Management of Chang Jung Christian University, Taiwan. He received his Ph.D. degree from the Education Management and Human Resources Department at Drake University, United States. His research interests include international business topics, strategic human resource management, organizational behavior, and leadership.

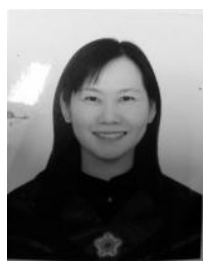

Hui Lin Chou is a doctoral student at the Graduate School of Business and Operations Management, Chang Jung Christian University, Taiwan. She received her master's degree from the Department of Public and Cultural Affairs at National Taitung University, Taiwan. Her research interests include human resource management, nursing management, and public policy.

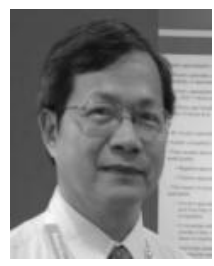

Jen Hwa Kuo is a doctoral student at the Graduate School of Business and Operations Management, Chang Jung Christian University, Taiwan. He received his M.S. degree from the Graduate Institute of Industrial Economics at National Central University, Taiwan. His research interests include enterprise resource planning, management information systems, and accounting.

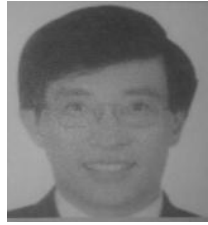

Ching Hsiang Hsieh is the hospital administrator of Chiayi Yang Ming Hospital. He received his M.D. degree from the School of Medicine Faculty Medicine of National Yang Ming University, Taiwan. He is also a clinical coodinator at Harvard University. 